\title{
Creating Impactful Model for Organizational Transformation
}

\author{
Andi Ilham Said*, Kartika Yuniarti \\ Sekolah Tinggi Manajemen PPM \\ Jakarta, Indonesia \\ *andiilhamsaid@gmail.com, tyq.ppm@gmail.com
}

\begin{abstract}
A big change can be occurred anytime and cannot be predicted. Every year, there will always be some markets that going through change, and organization must be ready to overcome this change for it to survive. The right processes is needed to help organizations face the market change. Therefore, transformation model is built aiming to accommodate the needs. Methods used in this research is quantitative methods with double regression hierarchy and SEM. As much as 229 respondents gathered, with majority of the respondents hold supervision or higher level position $(\mathbf{7 6 . 4 \%})$, and $88.1 \%$ of the respondents have been worked for more than 3 (three) years. This profile of the respondents generates beliefs that individuals participating in this research are competent enough to and appropriate to represent companies they worked for. Research findings suggest that there are 3 main factors in organizational transformation model, which consists of 9 elements. These factors are: Strategy Factors with Visionary Business Direction, Readiness to Change, Market Orientation, and Dealing with External Environment elements; Execution Factors with Operational Excellence, Strong Leadership, and Competent People elements; as well as Acceleration Factors with Risk Management, and Organization Culture elements. For business strategies to run efficiently, these factors give both direct support and impact to the business' strategies. Several factors, however, do not have a direct impact to and act as a booster and fasten the execution of business strategies.
\end{abstract}

Keywords-transformation, organization, change, strategic

\section{INTRODUCTION}

The simultaneously change in an internal and external environment of big organizations give rise to global business era, global market, information technology and quality strategic management, makes companies to act responsively to survive. Each companies have to be ready to face technological development, consumer's needs, and strict rivalry with other companies. The impact of environmental changes not only visible in organization's new paradigm but also affecting managerial changes, especially business strategies. Companies who eager to survive must act to these changes with their own strategies. Strategy implementation aims to reach a process to change or transformation to the extent of company's vision, mission, and goals. Therefore, strategy embodied in organizational changes and to reach competitive advantages. Porter, as cited in Kuswanto, competitive advantages are how a company truly implementing its general strategy into action [1]. General strategy implemented by a company in order to reach competitive advantages are low-on-cost strategy so they will be able to compete stronger, and product-differentiation strategy so consumers have sufficiently strong perceptions about products the company produce than its competitors.

Strategy, which set by top-level management and have high importance to organization's sustainability, act as main direction and organization's scope in the long term. Strategic management involved formulating and implementing strategies, which encourage organization to reach competitive advantages. This means that top-level management have to pick strategies or the most appropriate strategies to stay relevant and competitive in fluctuating environment. Many expert agrees that strategic planning have to be simple, realistic, and not too ambitious or not too demanding [2] Strategic planning, therefore, have to be made in certain ways for it to be flexible to accommodating environmental change and other effects that can influence current situation. Every organization have to manage their strategies in three main domains, namely in organization's internal resource, external environment in which organization operating, and organization's ability to add values to its activity. Moreover, factors applied in given time influenced strategic choices so it is important to the organization to preparing these choices well These factors include factors that coming from companies and industrial factors. Factors that stem for the companies include resource, organization structure, organization culture, and leadership. These factors become important part of implementing strategies effectively [2,3].

This is the main focus of this research, about how expected transformation model affect organization. Because it is important for an organization to survive and be prepared in facing changes, both external and internal changes.

\section{RESEARCH METHODS}

\section{A. Research Approach}

This research used quantitative approach and observing relations between each variable based on quantitative measurement. Moreover, this research aims to tests the hypothesis formed earlier. In the end, findings of this research describe causal relations of each variable through hypothesis testing. Meanwhile, data gathered in this research is primary and secondary data. Primary data acquired through questionnaire, while secondary data acquired through sources or other parties.

\section{B. Population and Sample}

The population of this research is Indonesian companies working in all industrial aspects (both manufacture and service 
sectors). The source of data gathering of this research relying more on PPM-Database, given some thoughts that the database has been verified for its accuracy and considered sufficient to represent companies located throughout Indonesia. Probability sampling technique is used in determining sample of this research. By using this technique, population members all assumed to have the same chance to be picked as research sample. Total data gathered for this research are 229 respondents.

\section{Data and Information Gathering Techniques}

To sustain the course of this research, data and information related to it are needed. Therefore, some techniques practiced in data and information gathering processes are:

- Primary data, researchers doing direct data gathering process through questionnaire given to the respondents. The questionnaire distributes online through Qualtrics. Questionnaire used in this research refer to and adapted from several sources. Likert scale ranging from $1-6$ is used in this questionnaire. This questionnaire means to assess to which extent is respondents agree on the statements proposed.

- Secondary data, acquired through literatures related to this research, both through literature reviews, articles, journals, and Internet websites.

\section{RESULTS AND DISCUSSION}

\section{A. Results}

1) Respondent and company's profile: Data source of the respondents of Transformation Research Model 2017 acquired from PPM Manajemen Database which act as a database and representing organizations in Indonesia. Data gathering process has been done in two phase. Phase one, questionnaire distribution through e-mail blast which each e-mail has their own respondent code, and phase two, e-mail follow up to remind respondents to fulfill the questionnaire. Data gathering has been done for 4 (four) months, from Jnauary through April 2017. As many as 306 respondents participating in this survey, but these 306 respondents still includes some of same companies. Therefore, researchers sort this data and calculate the average value of the entry from same companies because analysis unit in this research is organization. After the sorting process, 229 respondents considered eligible for this research.

As Figure 1 shows, majority of the respondents hold supervision or higher position $(76.4 \%)$, with supervisor $(37.4 \%)$, manager $(36.5 \%)$, and director or owner $(2.5 \%)$. As much as $88.1 \%$ of the respondents has been worked for more than 3 (three) years for the company. This respondent's profile generates beliefs that individuals participating in this research competent enough to and appropriate to represent each companies

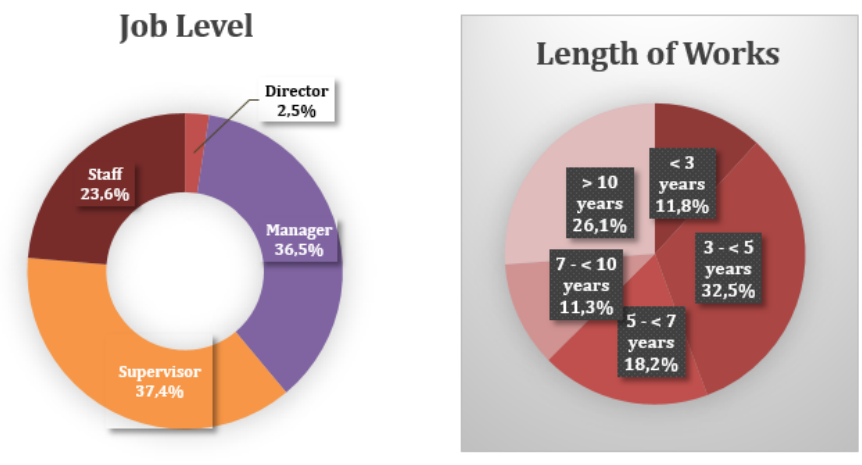

Fig. 1. Respondent profile.

Ownership status of the majority of respondents are National Private $(50.7 \%)$, followed by State-Owned Companies (18.7\%), Foreign Private (18.2\%), Bureaucracy $(10.7 \%)$, and District-Owned Companies (1.8\%). The scope of the kind of industries is enough to represents the kind of industries practiced in Indonesia as shown more detail on Figure 2.
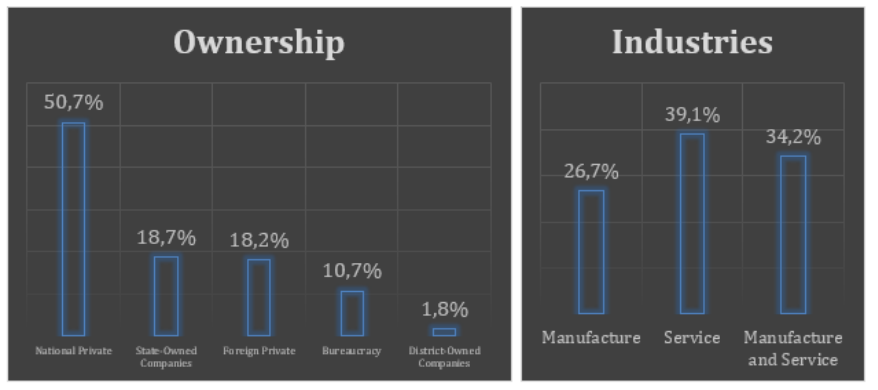

Fig. 2. Company's profile.

2) Research findings: Transformation model of indonesian companies. According to research findings, Transformation Model seen as two cogs connected with a belt. As appears on Figure 3 below, Transformation Model begins with the first cog which consists of three factors: strategy, execution, and acceleration factors. The second cog consists of competitive advantages. These cogs connected with a belt in the form of strategy effectiveness. If the three factors synergized, competitive advantages formed and create outputs in the form of transformation performance and effectivity, which is innovative, valuable, and sustainable companies (Figure 3). 


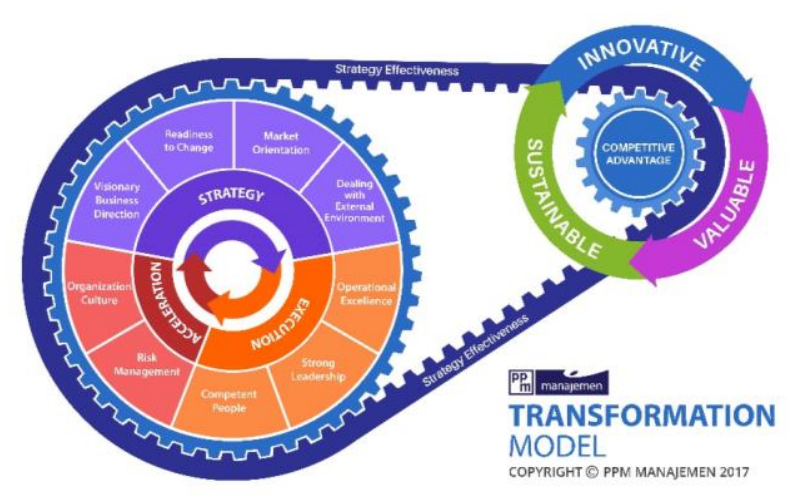

Fig. 3. Transformation model.

3) The relations of three-factors model and strategy effectiveness: In order to run effective business strategies, there are factors which give direct support and impact to business strategies. However, there are also factors which do not give direct impact to it and act as booster and accelerating the execution of the business strategies. These three factors, with 9 (nine) elements mentioned earlier, become the determinants in transformation (Figure 4). Each of these 9 (nine) elements have their own variables to describe its relational model to strategy effectiveness.

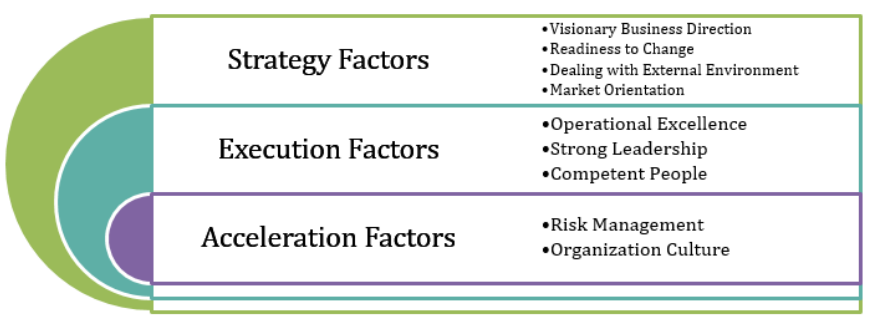

Fig. 4. Strategy effectiveness factors.

a) Strategy factors relational model: There are 4 (four) elements in strategy factor, which have direct relations and impact on strategy effectiveness, which consists of visionary business direction, readiness to change, dealing with external environment, and market orientation. Among these four elements, followings have greatest role in strategy effectiveness: visionary business direction (41.7\%). This, then, followed with readiness to change (18.7\%), dealing with external environment $(3.2 \%)$, and market oriented in the last place with $2.6 \%$ (figure 5 ).

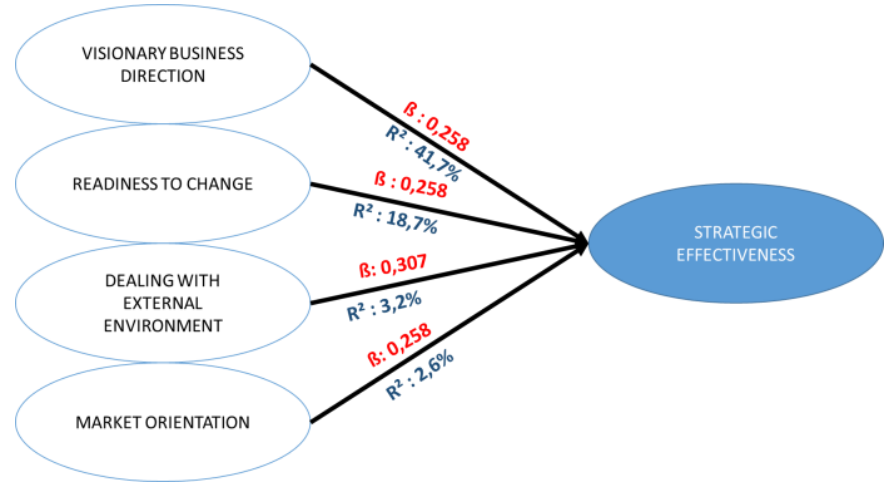

Fig. 5. Strategy factors relational model.

b) Execution and acceleration factors relational model: The next two factors are execution and acceleration factors, which consists of 5 elements. Elements on these factors connected to each other and have indirect relations to business strategies. Three relational models capturing the relations of the two factors well. That is, (1) relational model on competent people on strategy effectiveness mediated by organization culture; (2) relational model on strong leadership on strategy effectiveness mediated by organization culture, and (3) relational model on operational excellence on strategy effectiveness moderated by risk management.

In the first and second model, two elements in execution factor - competent people and strong leadership — mediated by organization culture. This means that the two elements do not have direct impacts on business strategy, they have to gone through the organization culture before they can influence business strategies. It is shown from the research that with the presence of organization culture in these elements, these elements have a bigger role on strategy effectiveness, each exert $39.7 \%$ role. The third model describe relational model on operational excellence on strategy effectiveness moderated by risk management. This means that operational excellence element will exert bigger role if its supported with risk management, which also strengthen its role on strategy effectiveness $(58.2 \%)$, compared to if it stands alone without risk management support (39.7\%) (Figure 6). 


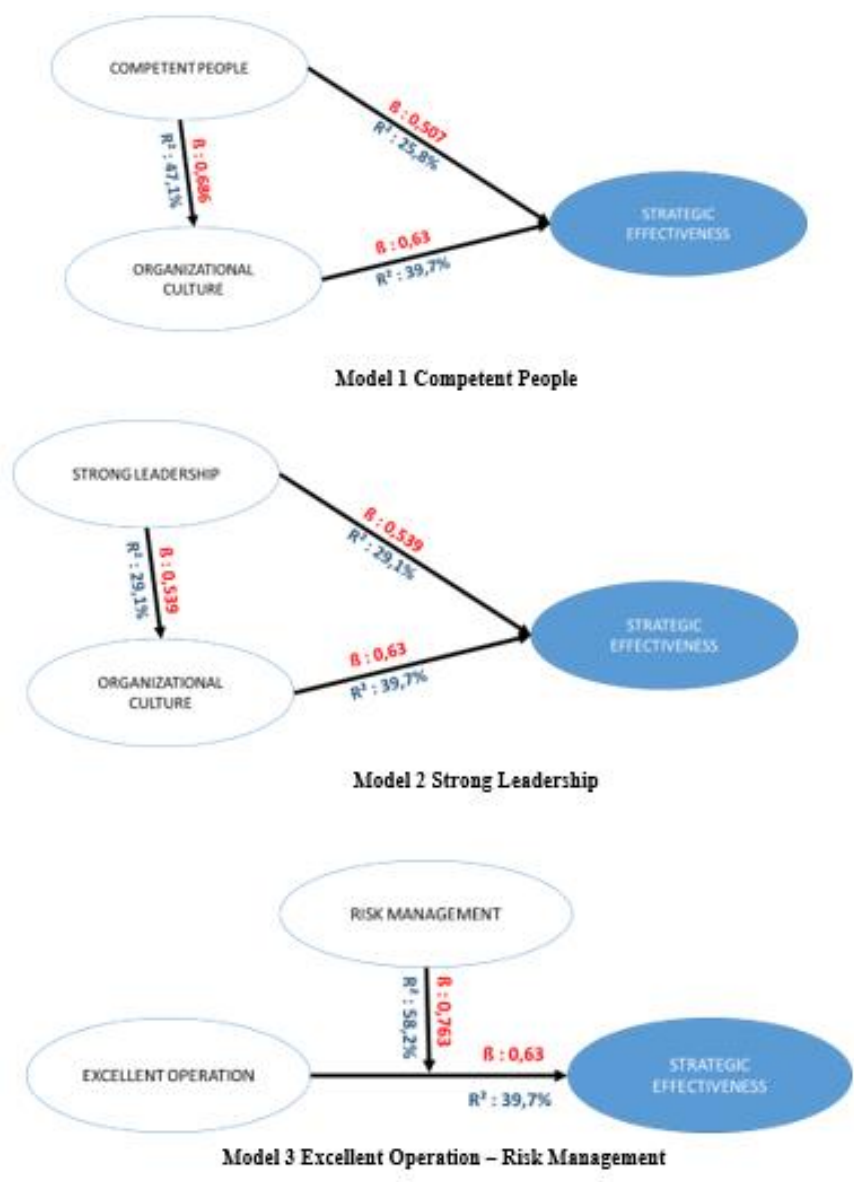

Fig. 6. Execution and acceleration factors relational model.

c) Strategy effectiveness relational model on competitive advantages affecting transformation performance: Research findings shows positive impacts of strategy effectiveness in competitive advantages a company has for $25.7 \%$, which eventually give impact on transformation performance. Competitive advantages acquired in transformation process have $35.8 \%$ of direct influence on transformation performance (Figure7).

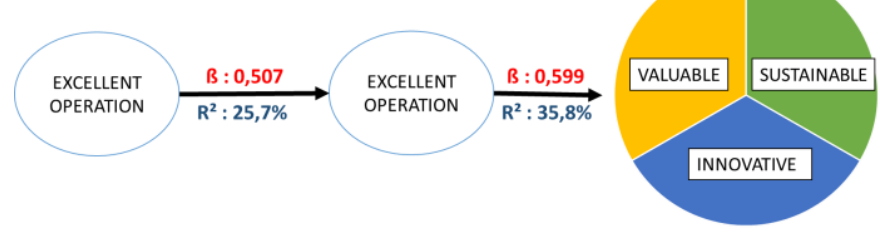

Fig. 7. Strategy effectiveness relational model on competitive advantages affecting transformation performance.

\section{CONCLUSION}

PPM Management's Transformation Model started from the consultation formulations and organizational experience PPM had, and then validated through deepening the theory and scientific research to make this model one solid model and can be implementing in many organizations to synchronize their business model with company's new strategies in order to become a competitive organization.

\section{REFERENCES}

[1] H. Kuswanto, "Dampak perubahan lingkungan bisnis terhadap perusahaan, organisasi, manajemen strategi dan akuntansi manajemen," DHARMA EKONOMI, vol. 20, no. 37, 2014.

[2] J.K. Kiptoo and F.M. Mwirigi, "Factors That Influence Effective Strategic Planning Process in Organizations," Journal of Business and Management, vol. 16, no. 6, pp. 188-195, 2014.

[3] N. Brinkschröder, Strategy Implementation: Key Factors, Challenges and Solutions. Faculty of Management and Governance. University of Twente. Netherlands, 2014. 